\title{
RECALL OF PAIRED-ASSOCIATES AS A FUNCTION OF OVERT AND COVERT REHEARSAL PROCEDURES
}

BY

JOHN W. BRELSFORD, JR. and RICHARD C. ATKINSON

TECHNICAL REPORT NO. 114

July 21,1967

PSYCHOLOGY SERIES

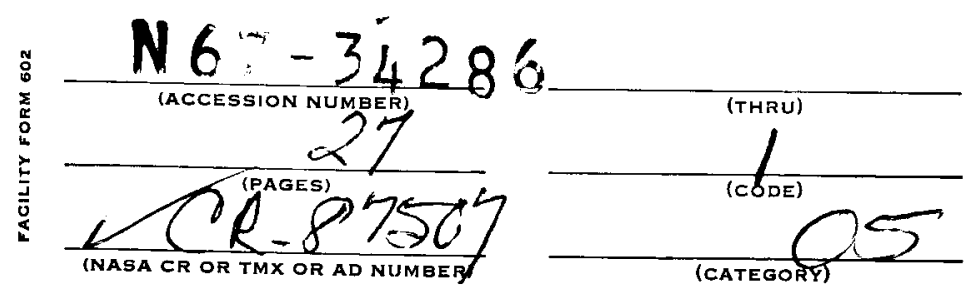

INSTITUTE FOR MATHEMATICAL STUDIES IN THE SOCIAL SCIENCES

STANFORD UNIVERSITY

STANFORD, CALIFORNIA 

RECALL OF PAIRED-ASSOCIATES AS A FUNCTION OF OVERT AND COVERT REHEARSAL PROCEDURES

by

John W. Brelsford, Jr. and Richard C.Atkinson

TECHNICAL REPORT NO. 114

July 21, 1967

PSYCHOLOGY SERIES

Reproduction in whole or in Part is Permitted for any Purpose of the United States Government

INSTITUTE FOR MATHEMATICAL SIUDIES IN THE SOCIAL SCIENCES

$$
\begin{aligned}
& \text { STANFORD UNIVERSITY } \\
& \text { STANFORD, CALIFORNIA }
\end{aligned}
$$




\section{Abstract}

The effect on memory of the mode of studying paired-associates was investigated using a continuous-presentation technique. Overt

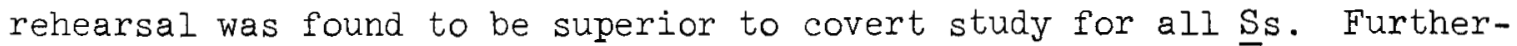
more, the form of the forgetting curve was qualitatively different for the two study procedures. The overt-rehearsal curve dropped slowly at first and then very rapidy defining an S-shaped function, whereas the curve for the covert-study condition decayed exponentially. A mathematical model employing a short-term rehearsal buffer and a long-term memory state accurately predicted the data obtained under the two study conditions. 


$$
\begin{aligned}
& \text { Recall of Paired-Associates as a Function } \\
& \text { of Overt and Covert Rehearsal Procedures I/ }
\end{aligned}
$$

John W. Brelsford, Jr. $2 /$ and Richard C. Atkinson

\section{Stanford University}

In several recent experiments (Atkinson, Brelsford, and Shiffrin, 1967; Brelsford, Keller, Shiffrin, and Atkinson, 1966) short-term memory for paired-associates has been examined using a continuouspresentation technique that provides for the efficient gathering of large amounts of data under fairly homogeneous conditions. In these experiments $\underline{S} s$ studied the paired-associate items in a covert manner only, i.e., no overt verbalization of the stimulus-response pairs occurred. It is of interest to determine whether performance in these experiments is a function of the particular mode of study. The present paper involves a within-subjects comparison of two types of study procedures, both using the continuous-presentation technique. On certain blocks of trials $\underline{S}$ s studied covertly as in the earlier experiments, while on other trial blocks Ss rehearsed overtly, vocalizing the stimulus-response pairs as they were presented for study.

\section{EXPERIMENT I}

$\underline{\text { Method }}$

Subjects. The Ss were eight students from Stanford University who received \$2 for each hour they participated in the experiment. Each $\underline{S}$ participated in eight l-hr. experimental sessions. 
Apparatus. The experiment was conducted in the Computer-Based Learning Laboratory at Stanford University. All programing, generation of stimuli, and response recording were carried out by computer programs running in a modified PDP-1 computer under the control of a time-sharing system. Stimuli were electronically generated and displayed on a cathode ray tube (CRT). Responses were made on an electric typewriter keyboard located immediately below the lower edge of the CRT.

Stimuli and Responses. The stimuli were six two-digit numbers randomly selected at the beginning of each experimental session from the set of all two-digit numbers between $O 1$ and 99 . Once a set of stimuli was selected for a given subject and session, it was used throughout that session. In every session the 26 letters of the alphabet were used as responses.

Procedure. Each experimental session lasted for 200 trials and was composed of four alternating 50-trial blocks of overt rehearsal trials (called 0-trials) and covert study trials (called C-trials). The initial 50-trial block for each session was randomly selected to be either an 0 - or a C-block. A session began with a series of six consecutive study trials; one study trial for each stimulus to be used during the session. The form of these initial study trials depended upon whether an $\mathrm{O}$ - or a $\mathrm{C}$-block had been selected to begin the session. If the session was to begin with a C-block, the word study appeared on the upper face of the CRT on each initial study trial. Beneath the word study there appeared one of the six stimuli to be used in the session, along with a randomly selected response. The $\underline{S}$ s had been initially instructed to try to remember, but not overtly rehearse, 
the association between the stimulus-response pairs that appeared with the word study. If the session was to begin with an 0-block, the word rehearse appeared above the word study on each initial study trial. Except for the word rehearse, 0-trials were identical to the C-trials. For these 0-trials $\underline{S}$ had been instructed to say aloud the stimulusresponse pair twice while it was on the CRT for study; furthermore, he had been instructed to pace himself so that his verbal rehearsal tended to fill the time period of the study trial. Each of the six initial study trials lasted for 3 sec, with a 3 -sec. intertrial interval (ITI)。 As soon as there had been one initial study trial for each of the six stimuli to be used in the session, the session proper began。

Each of the 200 trials in an experimental session involved a fixed series of events run off in the following order: 1) The word test appeared on the upper face of the CRT. Beneath the word test a randomly selected member of the 6 -item stimulus set appeared. The Ss had been instructed that, when the word test and a stimulus appeared on the CRT, they were to respond by pressing the appropriate key with the last response they had associated with that stimulus. The test portion of each trial lasted for 3 sec. 2) The CRT was blacked out for 2 sec. 3) The study portion of the trial occurred. 4) A 3-sec. ITI occurred ending the trial.

Just as in the initial study trials, the study periods were of two types. During blocks of C-trials, the word study appeared on the upper face of the CRT for 3 sec. Below the word study a stimulus-response 
pair appeared. The stimulus was the same one used in the preceding test portion of the trial. The new response for that stimulus was randomly selected for the response set, with the stipulation that the response be different from the immediately preceding response assigned to that stimulus. The O-blocks were identical to C-blocks except that on O-trials the word rehearse appeared above the word study. The SS followed the rehearsal instructions as described earlier. There was no break in the sequence of trials when switching from one study procedure to the other; thus items studied on the last few trials of an O-block tended to be tested during the C-block and visa versa.

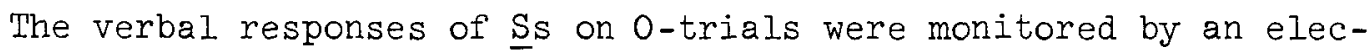
tronic intercommunication system. Because of warm-up and adaptation effects, data from the first experimental session for each $\underline{\mathrm{S}}$ are not presented. Data from the first 15 trials of each $\mathrm{C}$ - and $\mathrm{O}$-block were also discarded since we are not interested in results for stimulusresponse pairs that were studied under one experimental condition and tested on the other.

Results

In order to evaluate the over-all differences between overt and covert procedures, the proportion of correct responses for each of the experimental conditions was computed. Taking the average of these proportions over $\underline{S}$, the mean probability of correct response is .74 for the overt rehearsal condition and .58 for the covert study condition. The difference between the two conditions is highly significant, $\underline{t}(7)=4.05, \mathrm{p}<.01$ 
The number of trials intervening between study and test on a given stimulus-response pair will be referred to as the "lag" for that pair. Thus, if the test for a given pair occurs immediately following the study period for that pair, the lag is 0 . If one trial intervenes (involving both a test and study on another stimulus item), the lag is 1 , and so on. Since all of the stimulus-response pairs studied during 0-blocks can be considered as one experimental condition and those studied during C-blocks as a separate condition, it is possible to examine the proportion of correct responses for various lags under each experimental condition.

Figure 1 presents the relation between study mode and the probability of a correct response as a function of lag. In this figure each point is the mean proportion of correct responses for the eight Ss. It can be seen that the two lag curves are qualitatively quite different. The overt rehearsal curve drops slowly at first and then very rapidly, defining an S-shaped lag function, whereas the covert study curve drops abruptly between $\mathrm{lag} 0$ and $I$ and then decays exponentially. The curves are not displayed beyond lag 13 since there are too few observations.

\section{EXPERIMENT II}

Method

Because of the rather dramatic differences obtained in Exp. I, we decided to replicate the study using a slightly different procedure. Exp. II was identical to Exp. I in all respects except for the way the six stimuli were chosen. At the start of the first experimental session a set of six consecutive two-digit numbers was randomly 


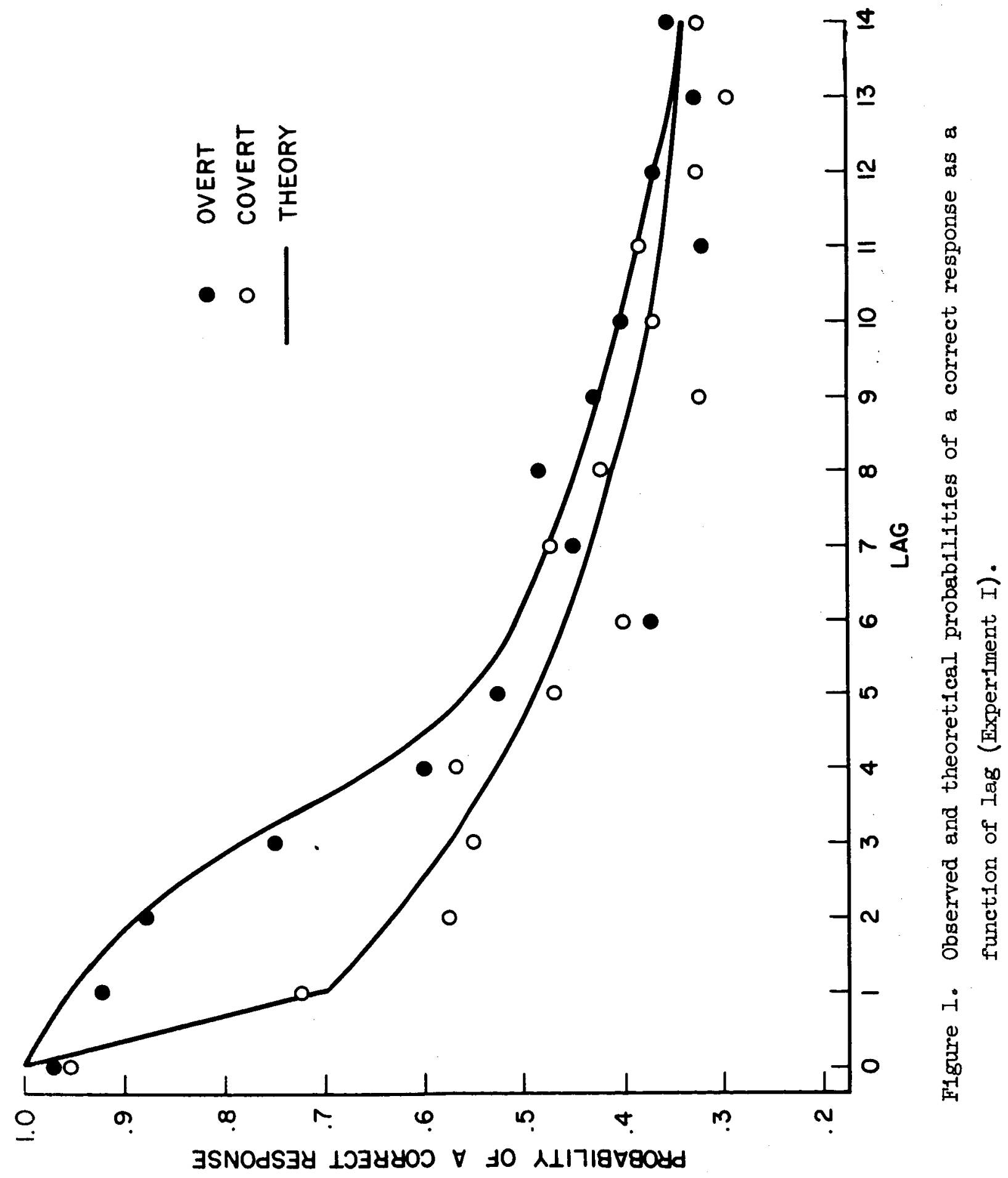


selected for each $\underline{S}$. These same numbers were then used as stimuli for that $\underline{S}$ throughout the experiment. This modification of the stimulus selection procedure was introduced in Exp. II to maximize the $\underline{S}^{\prime} \mathrm{s}$ familiarity with the stimulus set. Different subjects were used in experiments I and II.

$\underline{\text { Results }}$

As in Exp. I, the proportion of correct responses for each experimental condition was computed. Averaging over $\underline{S}$, the mean proportion of correct responses is .82 for the overt rehearsal condition and .63 for the covert study condition. As in Exp. I, this difference is highly significant, $\underline{t}(7)=4.72, \underline{p}<.01$. It also should be noted that the proportion of correct responses did not appear to depend upon the particular stimulus; i.e., it was about the same for all stimuli independent of their relative position in the set of six consecutive numbers.

Figure 2 presents the lag curves for Exp. II. It can be seen that they are very similar to those of Exp. I, except that the proportion of correct responses at a given lag is typically greater in the second experiment.

\section{DISCUSSION}

In these experiments it is clear that the recall of a pairedassociate item depends upon the manner in which it was rehearsed at the time of study. It is not surprising that items overtly rehearsed are recalled more often than those that are covertly studied. If nothing more, overt rehearsal insures that $\underline{\mathrm{S}}$ examines each stimulusresponse pair presented for study and rehearses it at least twice. 


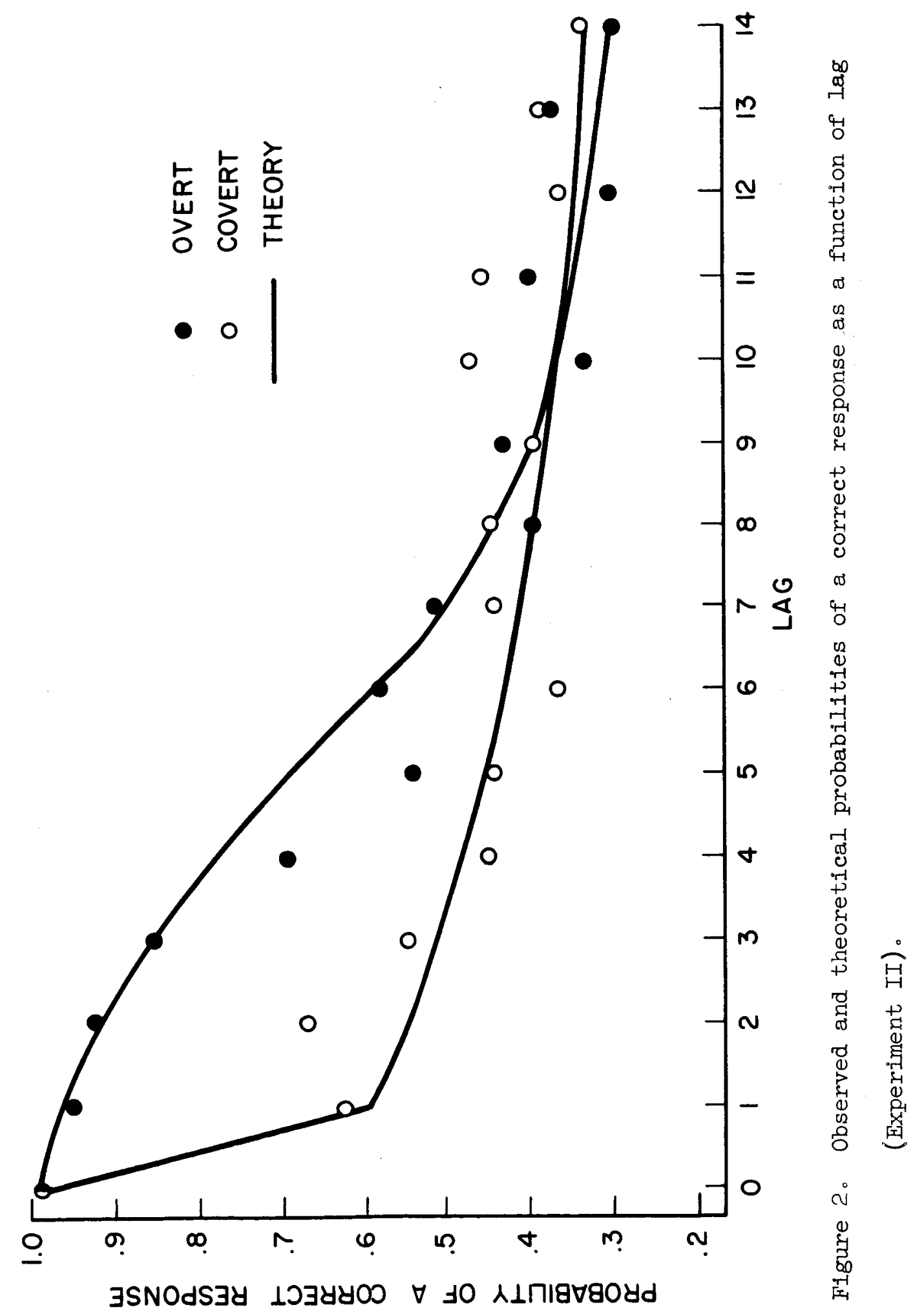


In the covert study situation there is the possibility that some items when presented for study may not be rehearsed and may possibly even be ignored. Of course, overt rehearsal could be detrimental to the extent that verbalization of a particular stimulus-response pair might disrupt a more general subvocal rehearsal scheme involving several items simultaneously. In the present case it appears that the advantages of overt rehearsal outweigh any disadvantages of covert study, because, for every

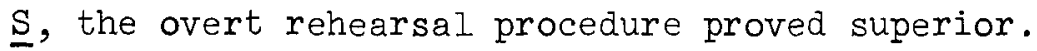

What is of more interest than the general finding that overt rehearsal is superior to covert study, is the specific interaction between the study procedure and the lag between study and test. It is of interest to determine whether this particular interaction can be predicted within the context of any extant theory of memory. In recent theoretical formulations of short- and long-term memory, Atkinson and Shiffrin (1965, 1967) and Atkinson, Brelsford, and Shiffrin (1967) proposed a model that is applicable to the present experiments.

The model assumes that data from studies of the type described here may be characterized by a two-stage process involving a short-term memory state called the "rehearsal buffer" and a long-term storage state. Since the experimental variables of interest involve only the rehearsal buffer, all we need say about long-term store is that it is characterized by the parameters $\theta$ and $\tau$, both of which are assumed to be the same for our two experimental conditions.

The rehearsal buffer is represented as a constant-size, push-down list that holds $r$ stimulus-response items simultaneously. Items are kept alive in this list via rehearsal. Since there are only $r$ items 
in the buffer at any one time, we must specify the rules by which items enter and leave the buffer. At the time a given stimulus-response item is presented for study, its stimulus member may or may not already be in the rehearsal buffer. If the stimulus is in the buffer, the new item being studied will enter the buffer and replace the corresponding stimulus-response item. If the item being studied is one whose stimulus member is not currently in the buffer, then the new stimulus-response item enters the buffer with probability $\alpha$, and some item currently in the buffer is knocked out. The value of the parameter $\alpha$ reflects the probability of entering a new item into the buffer. For example, $\alpha$ may depend on the ease with which new items can be integrated into on-going rehearsal schemes. If a particular set of items is easy to rehearse, the subject may not want to break up the combination to insert a new item. For the present experiments it is assumed that the overtrehearsal procedure will lead to an increase in the value of $\alpha$ when compared to the covert procedure.

The model outlined here is the same one used by Atkinson, Brelsford, and Shiffrin (1967) to provide an extremely accurate account of data from a series of studies employing the covert-study procedure of the present experiment. However, this version of the model will not fit the overt data because of the pronounced S-shaped form of the lag curve. Although increasing the value of $\alpha$ will predict better performance in the overt condition, the lag curve will have the form of an exponentially decreasing function, which is clearly not found in the data. In order to account for the S-shaped curve, we need to assume that in the overt condition $\underline{S}$ tends to eliminate the oldest items from the buffer first. 
In the model for the covert case, a new item entering the buffer is said to knock out at random any item currently in the buffer. It will be assumed for the overt case that an entering item tends to replace the oldest item in the buffer. The probability of eliminating an item from the buffer is specified as follows: if there are $r$ items in the buffer and they are numbered so that item $l$ is the oldest and item $r$ is the newest, then the probability that an entering item will knock the $j$ th item from the buffer is $\left[\delta(1-\delta)^{j-1}\right] /\left[1-(1-\delta)^{r}\right]$. This equation is derived from the following scheme: The oldest item is knocked out with probability $\delta$. If it is not eliminated, then the next oldest is knocked out with probability $\delta$. The process continues cyclically until an item is finally selected to be knocked out. When $\delta$ approaches zero, the knockout probabilities are random. When $\delta$ is greater than zero there will be a tendency for the oldest items to be eliminated from the buffer first; in fact, if $\delta$ equals one, the oldest item will always be knocked out. As shown in Atkinson and Shiffrin (1967), the higher the value of $\delta$ the greater the $S$-shaped effect predicted for the lag curve.

The model for the curves in Figs. 1 and 2 is therefore structured as follows: The parameters $r, \theta$, and $\tau$ will be assumed to be the same for the covert and overt study conditions; the parameters $\alpha$ and $\delta$ will be assumed to be affected by the experimental manipulation. To be precise, in the covert case $\alpha$ will be estimated freely and $\delta$ set equal to zero. In the overt case $\alpha$ will be set equal to one (which means that every item enters the buffer), and $\delta$ will be estimated freely. The parameter estimates $3 /$ that provide the best fit to the data 
of $\operatorname{Exp}$. I were $r=3, \theta=.97$, and $\tau=.90$; for the covert condition the estimate of $\alpha$ was .58 (with $\delta \rightarrow 0$ ), and for the overt condition the estimate of $\delta$ was .63 (with $\alpha=1.0$ ). The predictions for these parameter values are shown in Fig. I as smooth curves. A corresponding set of predictions was made for the data of Exp. II yielding $r=3$, $\theta=1.23$, and $\tau=.92$; for the covert condition the estimate of $\alpha$ was .63 (with $\delta \rightarrow 0$ ) and for the overt condition the estimate of $\delta$ was .51 (with $\alpha=1.0$ ). The predictions generated by these parameter values are presented in Fig. 2 as smooth curves. It can be seen that in both experiments the model is doing a reasonably good job of accounting for these data.

We now wish to examine a few additional aspects of the data from Exp. I. First we consider the "all-same" and "all-different" lag curves. Figure 3 gives the "all-same" lag curves for the overt and covert conditions. This curve gives the probability of a correct response for an item when all of the intervening items (between its study and test) have the same stimulus. Figure 3 also presents the "all-different" lag curves. This curve is the probability of making a correct response to a given item when the other items intervening between its study and test alI involve different stimuli. The predictions generated by the previous parameter values are given by the smooth curves; they appear to be quite accurate.

We now look for an effect that will be sharply dependent upon the value of $\alpha$ and hence differ for the overt and covert conditions. Such an effect is given in Fig. 4. Graphed there is the probability of a correct response to the last stimulus-response pair studied in a series 


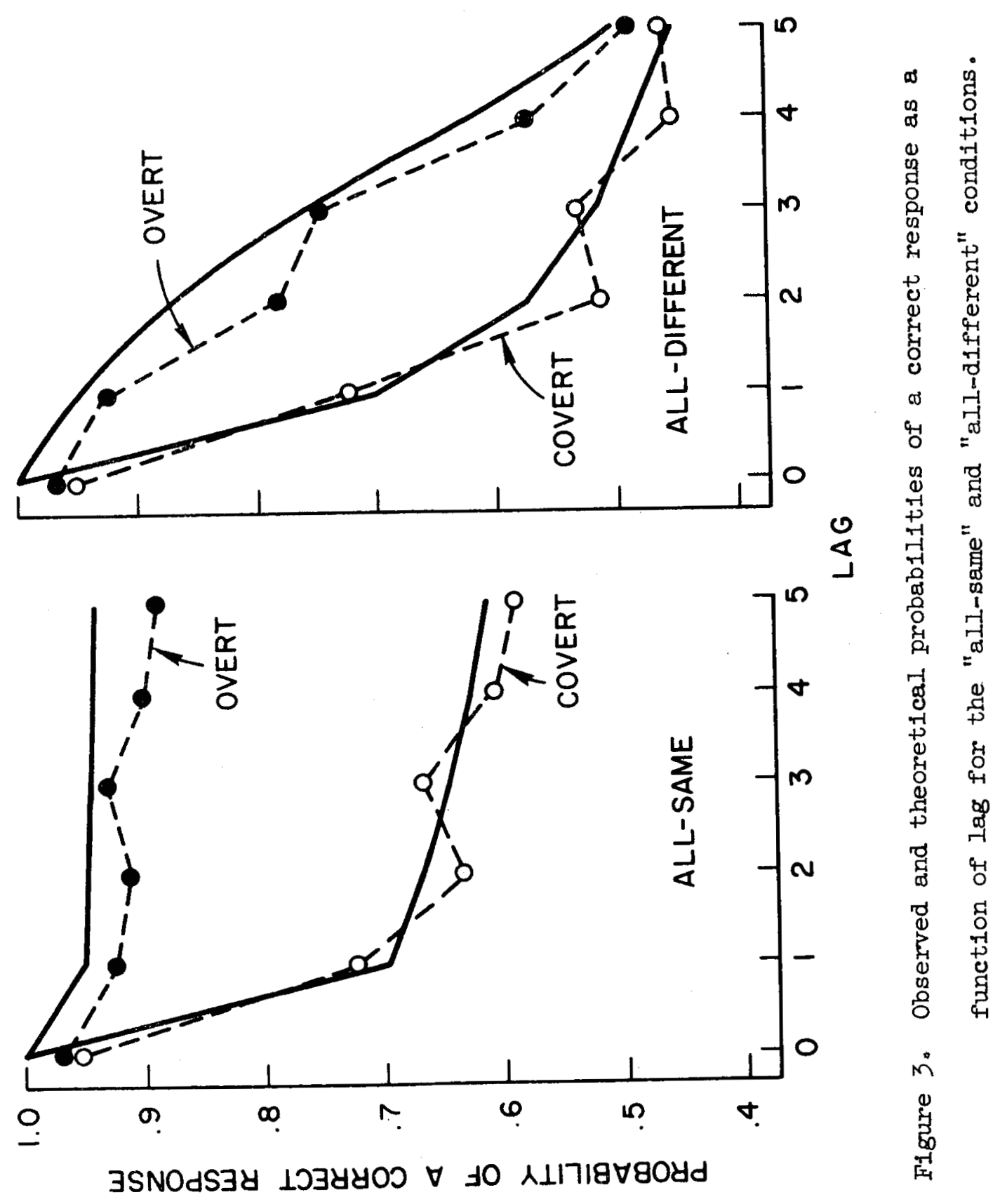


of consecutive trials involving the same stimulus; the probability correct is lumped over all possible lags at which that stimulus-response pair is subsequently tested. This probability is graphed as a function of the length of the consecutive mun of trials with the same stimulus. For example, if the study of item $42-B$ is preceded by three consecutive trials using stimulus 42 (but different responses), then what is being plotted on the ordinate is the probability of giving response $B$ to 42 when it is eventually tested and on the abscissa "three preceding items with the same stimulus." If $\alpha$ is less than one, then the length of the preceding sequence of items with the same stimulus will be an important variable. Since any item in the sequence which enters the buffer will cause every succeeding item in the sequence to enter the buffer, the probability that the item in question enters the buffer will approach one as the length of the preceding sequence of items all using the same stimulus increases. For $\alpha$ equal to one (overt condition), every item enters the buffer and therefore no change would be expected. As indicated in Fig. 4, the data and theory are in good agreement. The slight rise in the data points for the overt condition may indicate that an estimate of $\alpha$ slightly below 1.0 would improve the predictions, but the fit as it stands seems adequate. Because of space limitation we have not presented observed and theoretical values comparable to those in Figs. 3 and 4 for Exp. II. However, such analyses have been made, and the theoretical fits are as good as those obtained in Exp. I. 4 /

It should be noted that the theoretical curves presented in Figs. 3 and 4 do not involve new parameter estimates. The parameters used in generating these curves were the same ones used to fit the data of Fig. 1 . 


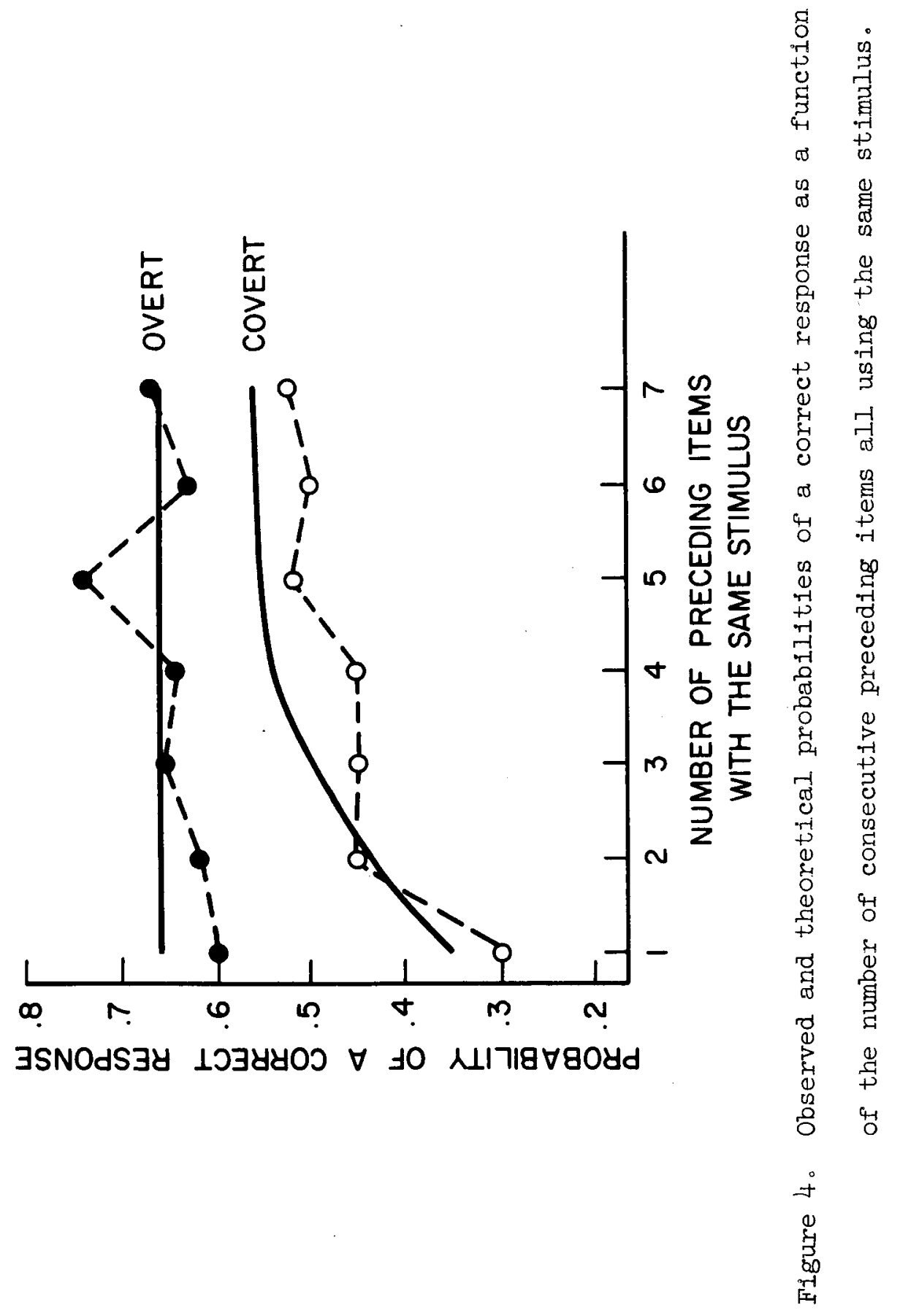


The close correspondence between the predicted and observed results provides strong support for the model. In our view the assumptions justified most strongly appear to be the fixed-size rehearsal buffer and the replacement assumptions governing the entry of new items into the buffer. It is difficult to imagine a consistent system without these assumptions that would give rise to similar effects. Some of the predictions supported by the data are not at all intuitive. For example, the phenomenon displayed in Fig. 4 seems to be contrary to predictions based upon considerations of negative transfer. Negative transfer would seem to predict that a sequence of items having the same stimulus but different responses would lead to large amounts of interference and hence reduce the probability of a correct response to the last item in the sequence. However, just the opposite effect was found in the covertstudy condition. Furthermore, the lack of an effect in the overt-study condition seems to rule out explanations based on successive correct responses or successive zero-lag tests. Intuition notwithstanding, this effect was predicted by the model. 


\section{Footnotes}

$I_{\text {This }}$ research was supported by the National Aeronautics and Space Administration, Grant No. NGR-05-020-036, and by U. S. Public Health Service Grant No. USPHS-MH-6154.

$2_{\text {Now at Yale University. }}$

$3_{\text {The estimation procedure uses a minimum chi-square method and is }}$ described in Atkinson, Brelsford, and Shiffrin (1967).

${ }^{4}$ The derivation of the theoretical functions presented in Figs. 3 and 4 are given in Atkinson and Shiffrin (1967). 
References

Atkinson, R. C., Brelsford, J.W., and Shiffrin, R. M. Multi-process models for memory with applications to a continuous presentation task. J. Math. Psychol., 1967, 4, 277-300.

Atkinson, R. C., and Shiffrin, R. M. Mathematical models for memory and learning. Tech. Rep. 79, Institute for Mathematical Studies in the Social Sciences, Stanford University, 1965. (To be published in D. P. Kimble (Ed.) Proceedings of the third conference on learning, remembering and forgetting. New York: New York Academy of Science.)

Atkinson, R. C., and Shiffrin, R. M. Human memory: a proposed system and its control processes. Tech. Rep. 110, Institute for Mathematical Studies in the Social Sciences, Stanford University, 1967. (To be published in K. W. Spence and J.T. Spence (Eds.) The psychology of learning and motivation: advances in research and theory, Vol. 2. New York: Academic Press.)

Brelsford, J. W., Jr., Keller, L., Shiffrin, R. M., and Atkinson, R. C。 Short-term recall of paired-associates as a function of the number of interpolated pairs. Psychon. Sci., 1966, 4, 73-74. 


\section{Figure Captions}

Figure 1. Observed and theoretical probabilities of a correct response as a function of lag (Experiment I).

Figure 2. Observed and theoretical probabilities of a correct response as a function of lag (Experiment II).

Figure 3. Observed and theoretical probabilities of a correct response as a function of lag for the "all-same" and "all-different" conditions.

Figure 4. Observed and theoretical probabilities of a correct response as a function of the number of consecutive preceding items all using the same stimulus. 


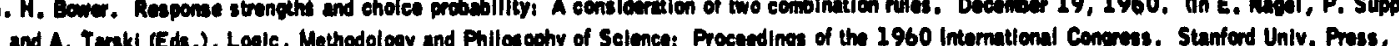
1962, Pp. 400-412)

6. H. Bower. Applleation of the all-er-none condltiening model to the leaming of compound responses. June 7, 1961.

P. Suppes and M. Schlag-Rey. Test of some leaming models for double contingent reinforcement. August 15, 1961. (Peychol. Rep., 1962,

P. Suppes and R. Gimaberg. A fundamental property of all-or-none modals, binomial distribution of reaponses prioe to condiltioning, with application to concept formation in chlldren. Soptamber 20, 1961. (Pyychol. Rev., 1963, 70, 139-161)

J. Theios. A three-state Markov model fo lexning. Septenber 22, 1961. (SImple conditioning as two-sten all-op-nome learning, Psychel. Rev., 1963, 70, 403-417)

G. H. Bower. General three-state Markov leaming models. Septeniber 26, 1961.

R. C. Atkinson. A variable threshold modal for slonal detection. November $17,1962$.

R. C. Atkimson. Mathematical models in research on perception and learning. Decenber 25, 1961, (in M. H. Marx (Ed.), Theories in Contemperary Psychology. New York: Macmillan Co., 1963. Pp. 551-564)

P. Suppes. Towards a behavioral foundation of mathematical proofs, January 2, 1962. (In K. Ajdukiewicz (Ed.), The Foundations of Statements and Decisions: Proceedings of the International Colloqulum on Methodology of Sclences, September 18-23, 1961. Warszawa: PWN-Poilish Sclentific Publishers, 1965. Pp. 327-341)

P. Suppes and J. L. Zinnes. Basic measurement theory. March 25, 1962. (Chapter I In R. R. Bush, E. H. Galanter, and R. D. Luce (Eds.), Handbook of Mathematical Psychology, Vol. I. New York: John Wiley, 1963)

R. C. Atkinson. E. C. Carterette, and R. A. Kinchla. Sequential phenomena in psychophysical judgments: a theonetical analysis. April 20, 1962. (Institute of Radio Engineers Transactions on Information Theory, 1962, IT-8, S 155-162)

R. C. Atkinson. A varlable sensitlvity theory of signal detection. May 18, 1962. (Psychol. Rev., 1963, 70, 91-106)

R. C. Atkinson and W. K. Estes. Stimulus sampling theory. July 1, 1962. (Chapter 10 In R. R. Bush, G. H. Galanter, and R. D. Luce (Eds.), Hantbook of Mathematical Psychology, Vol. II. Now York; Wiley, 1963)

P. Suppes, E. Crothers, R. Weir, and E. Trager. Some quantitative studies of Russian consonant phenome discrimination. Septenter $14,1962$.

R. C. Atkimson and R. C. Calfee. Mathematical learning theory. Jamuary 2, 2963. (n 8. B. Wolman (Ed.), Sclentifle Puycholory. Mem York: Basic Bocks, Inc., 1965. Pp. 254-275)

P. Suppes, E. Crothers, and R. Weir. Application of mathematical learning theory and linguistic analysis to vowal phomene matching in Russian words. December 28, 1962.

R. C. Attinson, R. Calfee, G. Sommer, W. Jeffrey and R. Shoemaker. A test of three models fer'stimulus compoumding with children. January 29 , 1963. U. exp. Psychol., 1964, 67, 52-58)

E. Crothers. General Markov models for learning with inter-trial forgetting. Aprill 8, 1963.

J. L. Myers and R. C. Atkinson. Choice behavior and rewaind structure. May 24, 1963. (Uoumal math. Pyychol., 1964, 1, 170-203)

R. E. Robinson. A set-theoretical approach to empirical meaningfuiness of measurement statements. Jume 10,1963.

E. Crothers, R. Weir and P. Palmer. The role of transcription In the learning of the orthographic representations of Russlan sounds. June $17,1963$.

P. Suppes. Problems of optimization in learning a list of simple items. July 22, 1963. (n Maynard W. Shelly, Il and Glema L. Bryan (Eds.), Human Judgments and Optimality. New York: Wiley. 1964. Pp. 116-126)

R. C. Atkinson and E. J. Crothers. Theoretical note: all-or-none leaming and intertrial forgetting. July $24,1963$.

R. C. Calfee. Long-term behavior of rats under probabilistic reinforcement schedules. October 1, 1963.

R. C. Atkinson and E. J. Crothers. Tests of acquisition and retention, axioms for paired-associate learning. October 25, 1963. CA comparison of paired-associate learning models having different acquisition and retention axioms, J. math. Psychol., 1964, 1, 285-315)

W. J. McGill and J. Gibbon. The general-gamma distribution and reaction times. November 20, 1963. W. math. Psychol., 1965, 2, 1-18)

M. F. Merman. Incremental leaming on random trials. Decenber 9, 1963. U. math. Psychol., 1964, $1, \overline{336}-351$ )

P. Suppes. The development of mathematical concepts in children. February 25,1964 . (On the behavioral foundations of mathematical concepts.

Monoy raphe of the Society for Resecirch In Child Development, 1965, 30, 60-96)

P. Suppes. Wathematical concept formation in children. Aprll 10, 1964. (Amer. Psychologist, 1966, 21, 139-150)

R. C. Calfee, R. C. Atkinson, and T. Shelton, Jr. Mathematical models for verbal learning. August 21, 1964. (In M. Wiener and J. P. Schoda (Eds.), Cybemetics of the Nervous System: Progress in Brain Research. Ansterdam, The Netherlands: Elsevier Pubilshing Co., 1965. Pp. 333-349)

L. Keller, M. Cole, C. J. Burke, and W. K. Estes. Paired associate learning with differential rewards. August 20, 1964, (Reward and information values of trial outcomes in paired assoclate learning. (Psychol. Monor., 1965, 79, 1-21)

M. F. Moman. A probabilistic model for free-responding. December 14, 1964 .

W. K. Estes and H. A. Taylor. Visual detection in relation to display size and redundancy of critical elements. January 25, 1965, Revised 7-1-65. (Perception and Psychophysics, 1966, 1, 9-16)

P. Suppes and J. Donio. Foundations of stimulus -sampling theory for continuous-time processes. February 9, 1965.

R, C. Atkinson and R. A. Kinchla. A learning model for forced-cholce detection experiments. February 10, 1965. (Br. J. math stat. Psychol., $1965,18,184-206)$

E. J. Crothers. Presentation orders for Items from different categories. March 10, 1965.

P. Suppes, G. Groen, and M. Schlag-Rey. Some models for response latency in paired-associates learning. May 5, 1965. W. math. Psychol.., $1966,3,99-128$

$M . V$. Levine. The generalization function in the probability learning experiment. June 3,1965 .

D. Hansen and T. S. Rodgers. An exploration of psychol inguistic units in Initial reading. July 6, 1965.

B. C. Anold. A correlated um-scheme for a continuum of responses. July 20, 1965.

C. Izama and W. K. Estes. Reinforcenent-test sequences in paired-associate learning. August 1, 1965.

S. L. Blehart. Pattern discrimination learning with Rhesus monkeys. September 1, 1965.

J. L. Phillips and R. C. Atkinson. The effects of display size on short-term memory. August 31, 1965.

R. C. Attins on and R. M. Shiffrin. Mathematical models for memory and learning. September 20, 1965 .

P. Suppes. The psychological foundations of mathematics. October 25, 1965. 
P. Suppes. Computer-assisted Instruction in the schools: potentialtites, problems, prospects. October 29, 1965.

R. A. Kinchia, J. Townsend, J. Yellott, Jr., and R. C. Atkinson. Influence of comolated visual cues on cuditory signal detectlon. November 2,

1965. (Perception and Psychophysies, 1966, 1, 67-73)

P. Suppes, M. Jerman, and G. Groen. Arithmetic drills and review on a computer-bused tolotype. November 5, 1963.

P. Suppes and L. Hyman. Concept learning with non-vorbal geometrical silmull. November 15, 1965.

P. Holland. A varlation on the m/nlmum chi-square test. November 18, 1965.

P. Suppes. Accelerated program In elementary $\rightarrow$ school mathematics -- the second year. November 22, 1965.

P. Lorenzen and F. Binford. Logic as a dialogleal game. November 29, 1965.

L. Keller, W. J. Thomson, J. R. Twoedy, and R. C. Atkinson. The effects of reinforcement interval on the acqulattion of palred-associate responses. December 10, 1963.

89 J. I. Yellott, Jp. Some effects on noncontingent success in human probability learning. December 15, 1965.

90 P. Suppes and G. Groen. Some counting models for first-grade performance data on simple addition facts. January 14, 1966.

91 P. Suppes. Information processing and choice behavior. January 31, 1966.

92 G. Groen and R. C. Atkinson. Models for optimizing the learning process. February 11, 1966.

93 R. C. Atkinson and D. Hansen. Computer-assisted Instruction In initlal reading: Staniord project. March 17, 1966.

94 P. Suppes. Probabllistic inference and the concept of tokal evidence. March 23, 2966.

95 P. Suppes. The axiomatle method in high-school mathematics. April 12, 1966.

96 R. C. Atkinson, J. W. Brelsford, and R. M. Shlffrln. Multi-process models for memory with applications to a continuous presentation task. April 13,1966.

97 P. Suppes and $E$. Crothers. Some remarks on stimulus-response theories of Janguage learning. June 12, 1966.

98 R. Bjork. All-or-none subprocesses in the learning of complex sequences. June 22, 1966.

99 E. Gammon. The statistical determination of linguistic units. July $1,1966$. 